\title{
Nucella lapillus L. imposex levels after legislation prohibiting TBT antifoulants: temporal trends from 2003 to 2008 along the Portuguese coast
}

\author{
Susana Galante-Oliveira, ${ }^{* a}$ Isabel Oliveira, ${ }^{a}$ Nelson Ferreira, ${ }^{a}$ José António Santos, ${ }^{b}$ Mário Pacheco ${ }^{a}$ \\ and Carlos Barroso ${ }^{a}$
}

\author{
Received 20th April 2010, Accepted 28th September 2010 \\ DOI: 10.1039/c0em00140f
}

\begin{abstract}
Nucella lapillus (dog whelk) imposex levels were assessed along the mainland Portuguese coast in 2006 and 2008 and were compared with available data from 2003 for the same area. Given that specimen size has been described as a factor inducing variation in some of the imposex assessment indices, and thus resulting in less reliable results, new monitoring and data analysis procedures are described and applied to study change of imposex levels from 2003 to 2008. A significant decline in imposex intensity was observed in the study area during the study period, and the Portuguese coast ecological status (under the terms defined by the OSPAR Commission) notably improved after 2003, confirming the effectiveness of the Regulation (EC) No. 782/2003 in reducing TBT pollution. Nevertheless, $N$. lapillus populations are still extensively affected by imposex, and fresh TBT inputs were detected in seawater throughout the coast in 2006. These recent inputs are attributed to vessels still carrying TBT antifoulants applied before 2003, as their presence in vessels was only forbidden in 2008. Considering that Regulation (EC) No. 782/2003 is an anticipation of the IMO global ban entered into force in September 2008, a worldwide-scale decrease in TBT pollution can be expected in the near future.
\end{abstract}

\section{Introduction}

For over four decades, tributyltin (TBT) compounds were extensively used as powerful biocides in antifouling (AF) paints applied to submerged structures to prevent bioincrustation. ${ }^{1}$ However, their extreme toxicity has resulted in numerous and widespread adverse biological effects in non-target organisms, namely imposex - the superimposition of male sexual characters, such as vas deferens and/or penis, onto prosobranch females. ${ }^{2,3}$ Extreme cases of complete female functional sterilization, population declines and extinctions were among the reported consequences of imposex in many species. ${ }^{4,5}$ In 2001 the International Maritime Organization (IMO) adopted the 'International Convention on the Control of Harmful Antifouling Systems on Ships' (AFS Convention), calling for a worldwide

${ }^{a}$ CESAM \& Department of Biology, University of Aveiro, 3810-193 Aveiro, Portugal. E-mail: susana.oliveira@ua.pt; Fax: +351 234426408; Tel: +351 234370350 ext. 22752

${ }^{b}$ ISEGI, New University of Lisbon, Campus de Campolide, 1070-312 Lisboa, Portugal prohibition on the application of organotins (OTs) as biocides in AF paints on ships by the effective date of 1 January 2003, and a complete banishment by 1 January $2008 .{ }^{6}$ However, this resolution could legally enter into force only 12 months after 25 states representing $25 \%$ of the world's merchant shipping tonnage had ratified it. Until then, the legal effect of 1 January 2003 would be suspended. Meanwhile, European Union (EU) countries anticipated the AFS Convention by implementing Regulation (EC) No. 782/2003, prohibiting the application or reapplication of TBT coatings on member states' national mercantile fleets and on ships operating under their authority, from 1 July 2003. The AFS Convention entry-into-force date was met on 17 September 2007, with the $25^{\text {th }}$ state ratification representing a total of $38 \%$ of the world's merchant shipping tonnage. ${ }^{7}$ As a result, TBT has been globally forbidden from 17 September 2008.

TBT compounds are on the Oslo and Paris (OSPAR) Commission 'List of chemicals for priority action's and also on the Water Framework Directive 2000/60/EC. ${ }^{9}$ Besides the chemical monitoring of TBT environmental concentrations, imposex assessment is also a mandatory element of OSPAR

\section{Environmental impact}

For over four decades, tributyltin (TBT) compounds were extensively used as biocides in antifouling paints. However, their extreme toxicity has resulted in numerous and widespread adverse biological effects, namely imposex - the superimposition of male sexual characters onto females. This phenomenon has been widely used in scientific research as a biomarker of environmental pollution by these compounds. This work describes the evolution of imposex levels along the Portuguese mainland coast between 2003 and 2008, evaluating the effectiveness of the strictest measure that banned TBT antifoulants in Europe (Regulation (EC) No. 782/2003), and creates an imposex level baseline at the moment when the international ban on TBT-based antifouling paints came into force, in September 2008. As some factors have been described to affect imposex assessment, which might result in less reliable results, new monitoring and data analysis procedures are also described. 
Co-ordinated Environmental Monitoring Programme (CEMP). ${ }^{10}$ Imposex development can be followed by the vas deferens sequence (VDS) and its intensity quantified, amongst other parameters, by using VDS classification schemes. For Nucella lapillus L. (dog whelk) a 7-stage scheme was proposed by Gibbs and co-authors: from 0 to 6 , in an increasing scale of female masculinisation. ${ }^{11}$ For a determined sample, the mean female VDS stage constitutes the VDS index (VDSI) which is an indication of imposex intensity in the sampled population. The other parameters recommended for monitoring of the biological effects of TBT pollution in this species are: mean female penis length (FPL), relative penis size index (RPSI), percentage of imposex affected females $(\% \mathrm{I})$ and percentage of sterile females $(\% \mathrm{~S}) .{ }^{11}$ The OSPAR Commission also adopted specific guidelines to monitor imposex in some gastropod species (see technical annex 3 of ref. 12) in which a clear indication is made regarding the use of $N$. lapillus as the main bioindicator. Also arising through the OSPAR CEMP, some assessment criteria for imposex in different species were developed and Ecological Quality Objectives (EcoQO) set. For $N$. lapillus these assessment criteria define 5 classes (A-E) through VDSI intervals (from VDSI $<0.3$ to VDSI $\geq 5$ ) and the EcoQO for imposex in this species corresponds to VDSI values below 2 (the limit between assessment classes B and C). As it was set for an extremely sensitive indicator, this EcoQO would measure the effectiveness of the international agreements to phase out and prohibit TBT-based AF paints usage, and the recovery progress of the marine environment from TBT presence. ${ }^{13-16}$
The current work aims to describe the evolution of imposex levels in Nucella lapillus populations along the Portuguese mainland coast between 2003 - the date when the Regulation (EC) No. 782/2003 was implemented - and 2008, in order to evaluate the effectiveness of the European legislation. The other objective is to create an imposex level baseline at the moment when the IMO TBT-based AF paints global ban came into force. As some factors have been described to induce variation in imposex assessment indices, ${ }^{17-21}$ which might result in less reliable results, new monitoring and data analysis procedures are described.

\section{Materials and methods}

\section{Sampling}

Since imposex expression follows sexual maturation, ${ }^{22}$ the minimum size at which Nucella lapillus specimens are sexually mature was studied within the study area. A large sample of animals of all sizes (from juveniles to adults) was collected in April 2006, at a single site located on the NW Portuguese coast $\left(40^{\circ} 31^{\prime} 05.90^{\prime \prime} \mathrm{N} 8^{\circ} 47^{\prime} 05.11^{\prime \prime} \mathrm{W}\right)$ near St. 9 (see Fig. 1A). Sampling was carried out right before the main spawning period described for the population at that site, ${ }^{20}$ a moment when all the adults are expected to be sexually mature.

For the assessment of long-term evolution of $N$. lapillus imposex levels in the Portuguese mainland coast, sites previously sampled in 2003 by Galante-Oliveira et al. ${ }^{23}$ were revisited in

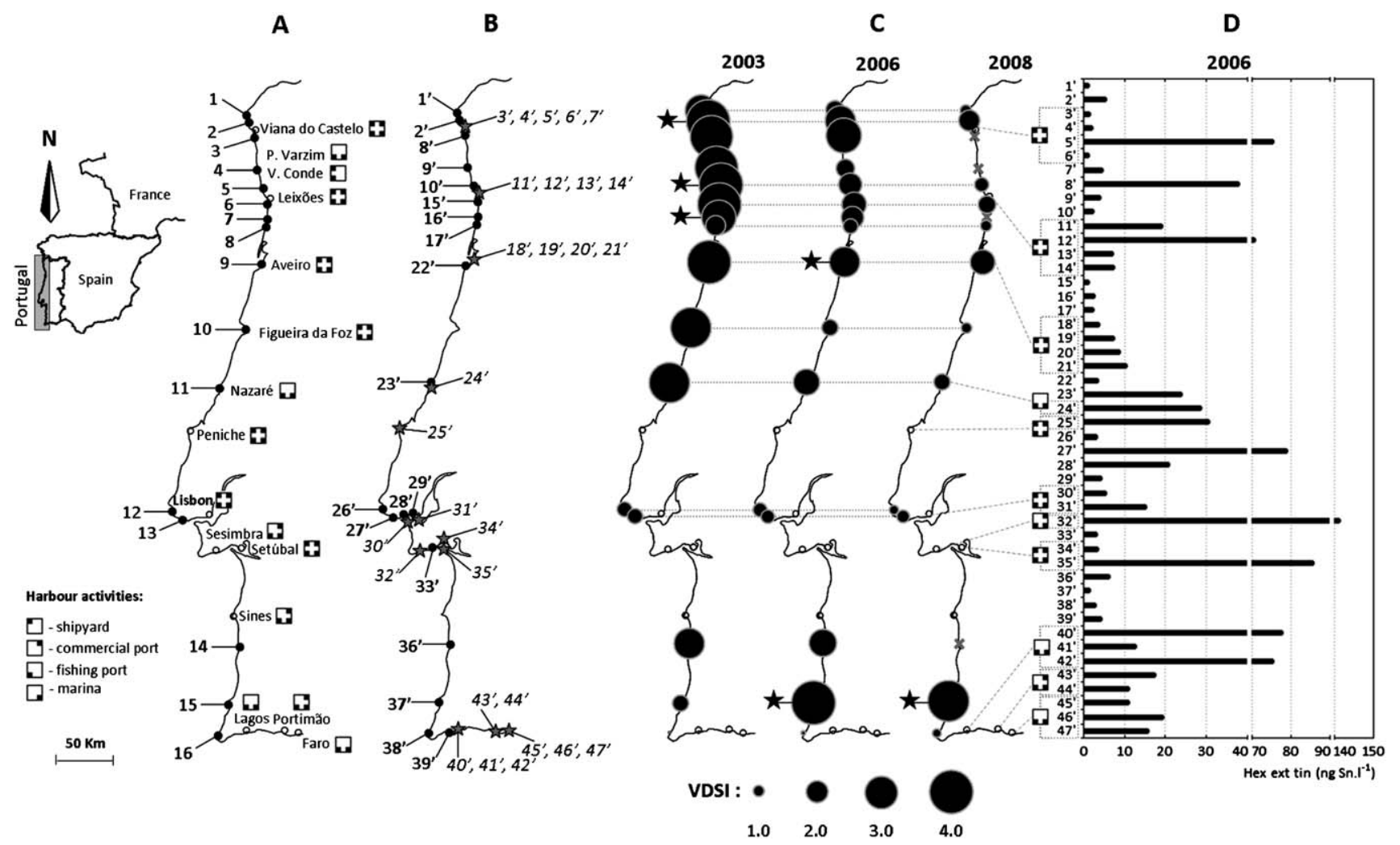

Fig. 1 Map of the NW Portuguese coast indicating: A. main harbour activities and sites (St. 1-16) where animals were collected for imposex levels assessment in 2006 and 2008; B. sites (St. $1^{\prime}-47^{\prime}$ ) where water samples were collected for OT quantification in 2006 (italic code numbers indicate sites located inside harbours, also indicated by $)$; C. Vas deferens sequence index (VDSI) and sterility occurrence ( $\star$ ) in females collected at St. 1-16 in $2003,{ }^{23} 2006$ and 2008; D. hexane-extractable tin (Hex ext tin) concentrations in water samples collected at St. $1^{\prime}-47^{\prime}$ in 2006. 
2006 and 2008: animals were collected at 16 sites (St. 1-16; Fig. 1A) from May to July 2006 and at 12 sites (St. 1, 2, 5, 6, 8-13, 15 and 16; Fig. 1A) from May to July 2008. Three time-searching periods, of $15 \mathrm{~min}$ each, were performed at each site: all the specimens (of all sizes) found were collected randomly, by hand, by the same person in 2006 and 2008. Additionally, in order to verify if TBT recent inputs still occur in the study area in July 2006, OT concentrations were determined in water samples collected at 47 sites (St. 1'-47'; Fig. 1B) on the lowest-tide level. Water sampling covered an extensive area of the Portuguese coast to allow a representative image of OT water contamination and its gradients and to identify the main pollution sources: sampling sites were spread not only across the Atlantic open coast but also in estuarine systems where the country major harbours are located (see Fig. 1A and 1B).

\section{Sexual maturation analysis}

The minimum shell height $(\mathrm{SH})$ at which animals are sexually mature was determined in specimens collected as referred to above. Animals SH (length from the apex to the siphonal canal) was measured with vernier callipers to the nearest $0.1 \mathrm{~mm}$. After shell removal, specimens were sexed and those that were parasitized were discarded. The complex gonad/digestive gland ( $\sim 1.0 \mathrm{~cm}$ of the animal proximal portion) was individually fixed in Bouin's solution for $24 \mathrm{~h}$ and then preserved in 70\% ethanol for histological analysis. Three slides with 4 gonad sections each were made by specimen, stained with haematoxylin-eosin and mounted in DPX resin for light microscopy observation, in order to determine individual gametogenesis stage. Gametogenesis classification for prosobranch gastropods was proposed by Barroso and Moreira ${ }^{24}$ and was applied to study the N. lapillus reproductive cycle by Galante-Oliveira et al. ${ }^{20}$ being therefore fully described for this species. Animals at stages I, II and III were grouped and classified as having gonad maturation GonadsMat 0 - 'immature', while specimens at gametogenesis stages IV, V and VI were classified as GonadsMat 1 - 'mature'. GonadsMat was plotted as a function of the respective animal $\mathrm{SH}$ and the minimum SH at which $100 \%$ of the specimens are sexually mature was graphically determined.

\section{Imposex analysis}

Imposex levels monitoring was carried out in samples collected in 2006 and 2008 along the Portuguese coast (Fig. 1A). Specimen SH was measured with vernier callipers to the nearest $0.1 \mathrm{~mm}$. Animals were separated into SH classes of amplitude $2.50 \mathrm{~mm}$, from a minimum of $5.00 \mathrm{~mm}$ to the maximum size collected at each site: 30.9, 26.7, 27.4, 27.2, 27.5, 31.4, 34.5, 34.0, 33.2, 26.3, $22.1,21.6,23.7,32.4,26.6$ and $25.0 \mathrm{~mm}$ at sites $1-16$, respectively, in 2006; and 29.4, 24.8, 28.5, 30.3, 29.5, 40.3, 26.3, 23.9, 24.3, 25.0, 26.8 and $29.7 \mathrm{~mm}$ at sites $1,2,5,6,8-13,15$ and 16 , respectively, in 2008. After shell removal and (whenever available) 10 specimens per SH class were sexed and those that were parasitized were discarded from the analysis. The penis length (PL) was measured using a stereo microscope with a graduated eyepiece to the nearest $0.14 \mathrm{~mm}$ and the female vas deferens sequence (VDS) was classified according to the scheme proposed by Gibbs et al. ${ }^{11}$ For animals with $\mathrm{SH} \geq 17.50 \mathrm{~mm}$ (minimum SH at which animals are sexually mature; see the Results section) the following parameters were determined for each sample: mean male and female penis length (MPL and FPL, respectively), relative penis size index $\left(\mathrm{RPSI}=\mathrm{FPL}^{3} \times 100 / \mathrm{MPL}^{3}\right)$, vas deferens sequence index (VDSI), percentage of imposex-affected females $(\% \mathrm{I})$ and percentage of sterile females $(\% \mathrm{~S})$.

\section{Hexane-extractable tin concentrations in water}

Samples of 21 of sub-surface $(15 \mathrm{~cm}$ depth) water were collected in two 11 glass bottles, previously washed in $0.5 \%$ hydrochloric acid $(\mathrm{HCl})$. Immediately before each sample collection, bottles were rinsed with local water. Samples were then acidified with $5 \mathrm{ml}$ concentrated $\mathrm{HCl}$ per litre. Methods used for extraction (from unfiltered water) and OTs analysis are those described by Bryan et al. ${ }^{4}$ providing a detection limit of about $0.2 \mathrm{ng}$ of Sn per 1. However, washing of hexane extracts with $1 \mathrm{~N}$ sodium hydroxide $(\mathrm{NaOH})$ to separate dibutyltin (DBT) from the TBT fraction was not performed; hence values are reported as hexaneextractable tin, as we only aim to depict any recent OT inputs into the study area in 2006.

\section{Statistical data analysis}

The evolution of imposex levels in $N$. lapillus adults $(\mathrm{SH} \geq$ $17.50 \mathrm{~mm}$ ) between 2003 and 2008 was performed using two different approaches depending on whether sampling sites were analysed together or separately. In the first approach, the subjects were the 12 sampling sites common to 2003, 2006 and 2008 (St. 1-2, 5-6, 8-13 and 15-16; Fig. 1A) and the observations were the mean female SH (\$SH), VDSI, mean FPL or \%I at each site; the purpose of the analysis was to test if the mean iSH, the VDSI, the mean FPL and the \%I of all sites together changed significantly (representing the entire study area over the studied period) using the repeated-measures Friedman test followed by the post-hoc Dunn's test for multi-comparisons. The second approach was applied to evaluate changes in imposex intensity at each site from 2003 to 2008 . In this case, the subjects were the specimens analysed per site (with $\mathrm{SH} \geq 17.50 \mathrm{~mm}$ ) and the observations were the assessed individual parameters [each male $\mathrm{SH}\left({ }^{\star} \mathrm{SH}\right)$, each $9 \mathrm{SH}$, each animal PL and the VDS stage exhibited by each female] i.e., samples were assumed to be independent since specimens collected randomly over time were not the same; a non-parametric Kruskal Wallis test, followed by the post-hoc Dunn's test for multi-comparisons, was applied in this case. Since St. 3-4, 7 and 14 were only sampled in 2006, the Mann-Whitney U-test was used to compare individual parameters between $2003^{23}$ and 2006 in these cases. SigmaStat v2.0 software was used to compute these analyses. Since the SH of animals sampled in the different surveys was not constant, and it is known that the PL may also depend on specimen size, statistical comparisons using the penis-based RPSI were not performed. Additionally, a different statistical procedure to remove the effect of animal size on imposex temporal trends was used: the ordered logit regression model was applied to study change in imposex levels from 2003 to 2008, using all the animals collected at each site (from juveniles to adults and not only the ones with $\mathrm{SH} \geq 17.50 \mathrm{~mm}$ ). The ordered logit regression belongs to the family of the generalized linear models and 
specifically to the models for categorical responses. These models are the best way to deal with special kinds of response variables arising from classification, count processes, and so on. A seminal book about these models is by Maddala, ${ }^{25}$ and further details can be found in Agresti ${ }^{26}$ and Long. ${ }^{27}$ As mentioned above, imposex development can be followed by the vas deferens sequence (VDS) and its intensity quantified by using VDS classification schemes. In $N$. lapillus, the variable 'VDS' has seven categories. ${ }^{11}$ 'VDS' can be considered an ordinal variable in the sense that each of its values evaluates a certain degree of the continuous process of the female virilization. Obviously, this continuous process can not be evaluated or measured in a continuous scale, so it is a latent, non-observable, variable. Therefore, the ordered logit regression seems to be the more adequate, accurate and powerful model to make the statistical analysis of this process evolution. This can be seen ahead in the Results section. This statistical procedure was implemented trough $R$ programming (see http://www. r-project.org) using 'MASS' library. $R$ is a powerful opensource language and environment for statistical computing. The authors are willing to provide the programming code to those interested (josant.santos@gmail.com).

Table 1 Nucella lapillus male and female mean shell heights ( $₫ \mathrm{SH}$ and $9 \mathrm{SH}$; expressed in millimetres) and the number of specimens with $\mathrm{SH} \geq 17.50$ $\mathrm{mm}$ analysed for imposex $(n)$ are presented per sampling site (St. code and name) and year. The total number of specimens found during the timesearching period of $3 \times 15 \mathrm{~min}\left(\mathrm{n} 45^{\prime}\right)$ is also indicated per site and year. ${ }^{\prime} \mathrm{SH}$ and ${ }^{\mathrm{S}} \mathrm{SH}$ were statistically compared and the respective significance is indicated by asterisks $\left(^{*}\right)$ next to the last year of the tested pair (i.e., if the 2003 value is significantly different from the 2006 one, asterisks are indicated next to the 2006 value). Data for 2003 were published by Galante-Oliveira et al. ${ }^{23}$ For additional data on sites location see Fig. 1A.

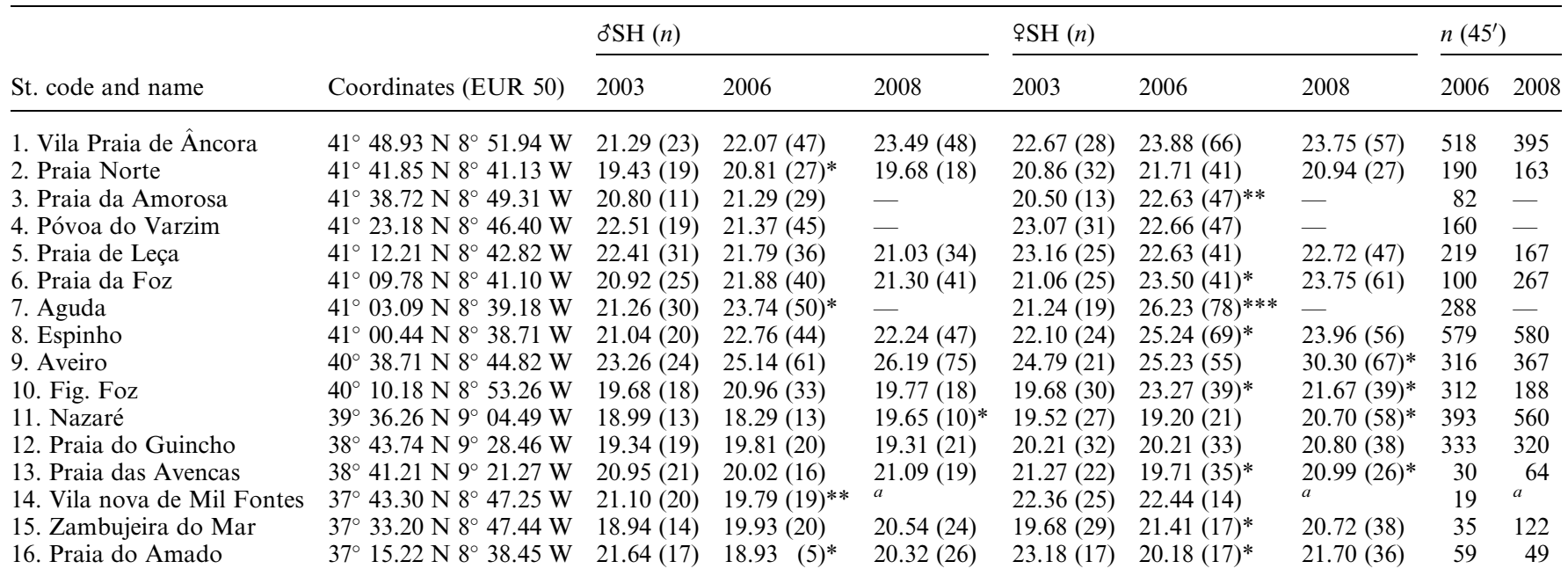

${ }^{a}$ Animals not found; *: $p<0.05 ; * *: p<0.01 ; * *: p<0.001$.

Table 2 Nucella lapillus mean male and female penis length (MPL and FPL), relative penis size index (RPSI), vas deferens sequence index (VDSI) and percentage of imposex-affected females (\%I) indicated per sampling site (St.) and year. MPL, FPL, RPSI and VDSI of specimens with SH $\geq 17.50 \mathrm{~mm}$ were statistically compared and the respective significance is indicated by asterisks $(*)$ next to the last year of the tested pair (i.e., if the 2003 value is significantly different from the 2006 one, asterisks are indicated next to the 2006 value). Data for 2003 were published by Galante-Oliveira et al. ${ }^{23}$ For additional data on sites location see Fig. 1A.

\begin{tabular}{|c|c|c|c|c|c|c|c|c|c|c|c|c|c|c|c|}
\hline \multicolumn{4}{|c|}{ MPL (mm) } & \multicolumn{3}{|c|}{ FPL (mm) } & \multicolumn{3}{|c|}{ RPSI ( $\%)$} & \multicolumn{3}{|c|}{ VDSI } & \multicolumn{3}{|l|}{$\% \mathrm{I}$} \\
\hline 2 & 2.97 & 3.16 & 3.24 & 2.02 & $0.65^{*}$ & 0.43 & 31.43 & 0.87 & 0.23 & 4.00 & $2.78^{*}$ & $1.93^{*}$ & 100.0 & 100.0 & 100.0 \\
\hline 3 & 3.31 & $3.95 * *$ & - & 1.97 & $0.99 * * *$ & - & 20.95 & 1.57 & - & 3.92 & $3.23^{*}$ & - & 100.0 & 100.0 & - \\
\hline 4 & 3.33 & $3.94 * * *$ & - & 1.67 & $0.36^{* * *}$ & - & 12.72 & 0.08 & - & 3.94 & $1.66^{* * *}$ & - & 100.0 & 100.0 & - \\
\hline 5 & 3.44 & $4.55^{*}$ & 4.40 & 2.04 & $0.69^{*}$ & $0.18^{*}$ & 20.95 & 0.35 & 0.01 & 4.04 & $2.10^{*}$ & $1.28^{*}$ & 100.0 & 100.0 & 95.7 \\
\hline 8 & 3.40 & $4.48^{*}$ & $3.86^{*}$ & 0.60 & $0.21^{*}$ & 0.10 & 0.55 & 0.01 & 0.00 & 1.83 & 1.38 & $1.02 *$ & 91.7 & 100.0 & 83.9 \\
\hline 9 & 2.93 & $3.79^{*}$ & $4.67 *$ & 2.40 & $0.97^{*}$ & 0.77 & 54.72 & 1.67 & 0.44 & 4.00 & $2.82 *$ & 2.27 & 100.0 & 100.0 & 100.0 \\
\hline 10 & 3.47 & $4.33 *$ & 3.88 & 1.31 & $0.25^{*}$ & 0.09 & 5.43 & 0.02 & 0.00 & 3.73 & $1.46^{*}$ & 0.95 & 100.0 & 100.0 & 82.1 \\
\hline 11 & 3.41 & $4.11 *$ & 3.88 & 1.56 & $0.82 *$ & $0.25^{*}$ & 9.65 & 0.80 & 0.03 & 3.70 & $2.38 *$ & $1.48 *$ & 100.0 & 100.0 & 96.6 \\
\hline 12 & 3.42 & $4.07 *$ & 4.52 & 0.36 & 0.10 & 0.02 & 0.12 & 0.00 & 0.00 & 1.38 & 1.27 & 0.84 & 84.4 & 100.0 & 78.9 \\
\hline 13 & 2.63 & 2.56 & $4.78^{*}$ & 0.28 & 0.09 & 0.10 & 0.12 & 0.00 & 0.00 & 1.41 & 1.23 & 1.15 & 77.3 & 100.0 & 96.2 \\
\hline 14 & 3.37 & 3.53 & $a$ & 1.05 & $0.65^{* *}$ & $a$ & 3.05 & 0.63 & $a$ & 2.80 & 2.50 & $a$ & 100.0 & 100.0 & $a$ \\
\hline
\end{tabular}

${ }^{a}$ Animals not found; *: $p<0.05 ; * *: p<0.01 ; * *: p<0.001$. 

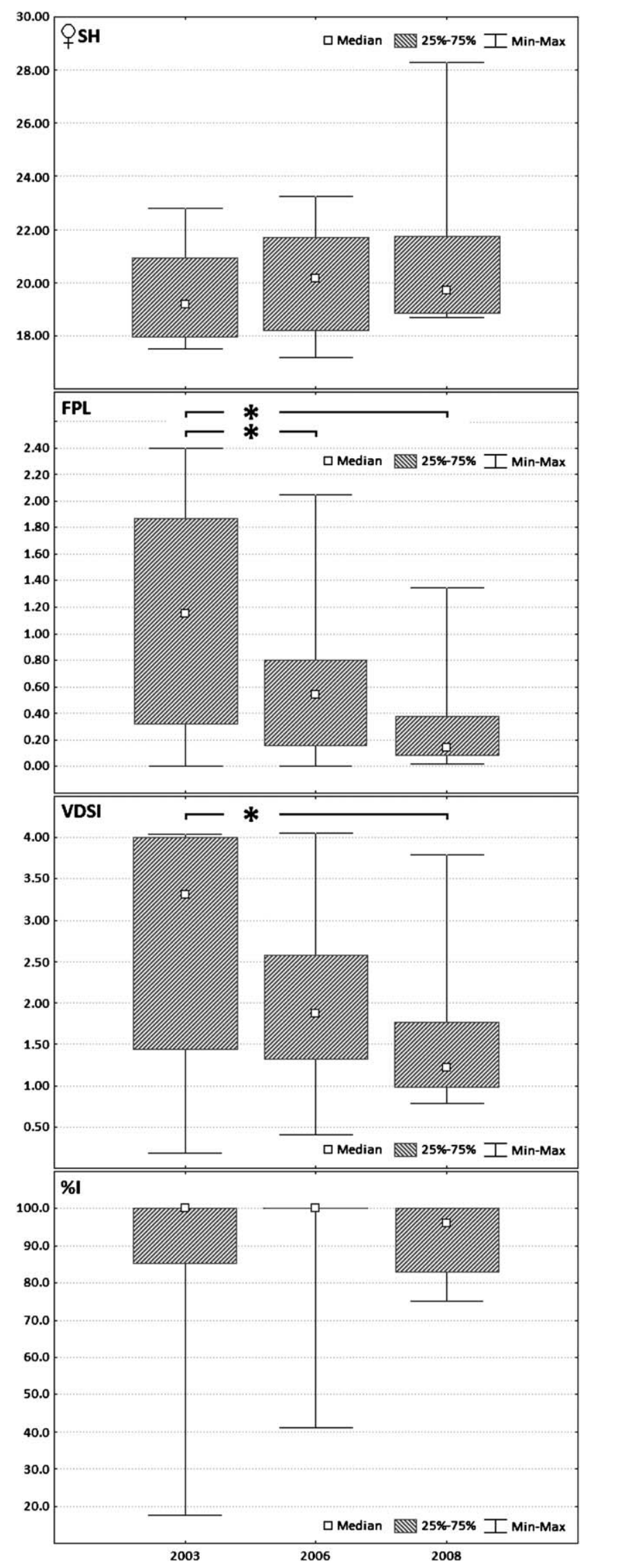

\section{Results}

The minimum $\mathrm{SH}$ at which $N$. lapillus specimens are sexually mature (GonadsMat 1) was graphically determined as being $17.50 \mathrm{~mm}$ for the given sampling site. As we could not determine this parameter for all sites along the Portuguese coast, we assumed the same value for the entire study area, and so imposex indices were calculated for specimens of $\mathrm{SH} \geq 17.50 \mathrm{~mm}$. The number of specimens used per gender, sampling site and year are presented in Table 1 together with the respective mean ot SH and iSH. The number of specimens collected at each site during a period of $45 \mathrm{~min}$ is also indicated in Table 1. No correlation was found between imposex levels and $N$. lapillus abundance at each site, and also no temporal trend was observed: the number of specimens collected during 45 min increased at St. 6, 9, 11, 13 and 15 from 2006 to 2008; decreased at St. 2, 5 and 10; and was approximately constant at St. 8, 12 and 16.

MPL, FPL, RPSI, VDSI and \%I values are shown in Table 2. Additionally, the temporal evolution of VDSI at each site and concentrations of hexane-extractable tin in 2006 are represented in Fig. 1C and 1D, respectively. Data for $2003^{23}$ were reorganized and imposex indices recalculated using only animals of $\mathrm{SH} \geq$ $17.50 \mathrm{~mm}$ (no significant differences between Galante-Oliveira et al. ${ }^{23}$ values and the recalculated ones were observed). A general decrease in imposex indices (apart from \% $\mathrm{I}$ ) is evident along the entire coast, with the exception of St. 15 and 16. Sterile females were recorded at St. $9(5.5 \%)$ and $15(11.8 \%)$ in 2006 and at St. 15 $(26.3 \%)$ in 2008. Recent inputs of organic tin were detected in the whole study area in 2006, with hexane-extractable tin concentrations in water ranging from 0.7 to $140.8 \mathrm{ng} \mathrm{Sn}$ per 1 . Furthermore, sampling sites were grouped regarding their location relative to harbours: (1) sites located less then 1 mile from the main port infrastructures (St. 2-3, 5-6, 9-11 and 13); (2) sites around small boat mooring facilities (St. 1, 4, 7-8 and 14-15); and (3) sites at pristine areas (St. 12 and 16). VDSI registered in 2006 and 2008 was compared between these three groups of sites by the one-way ANOVA method, after confirming the data normality and homoscedasticity. There is a significant difference in imposex intensity between groups $(s=3.6754, p<0.05)$ and the post-hoc Fisher LSD test revealed that the difference is between the first group (sites near harbours) and the other two $(p<0.05)$.

When the 12 sampling sites - common to 2003, 2006 and 2008 (St. 1-2, 5-6, 8-13 and 15-16; Fig. 1A) - are analysed together, no significant difference in $\mathrm{PSH}$ is observed from 2003 to 2008 (Friedman's test: $s=3.106, p=0.212$ ) and a global decline in both VDSI $(s=12.167, p=0.002)$ and FPL $(s=11.617, p=$ 0.003 ) is detected (Fig. 2). Dunn's multi-comparisons tests between different years show that there was a significant reduction of VDSI and FPL levels from 2003 to 2008 and also of FPL

Fig. 2 Global temporal trend of female shell height ( $\$ \mathrm{SH})$ and imposex levels (FPL, VDSI and \%I) exhibited by specimens collected at 12 common sites along the NW Portuguese coast: for statistical analysis St. $1,2,5,6,8-13,15$ and 16 were pooled and the median was calculated for each year $-2003,{ }^{23} 2006$ and 2008. The significance of the Dunn's test for multiple comparisons between years is indicated on the respective plot $(*$ : $p<0.05)$. 
from 2003 to 2006 (Fig. 2). Nevertheless, no significant difference in \%I is observed from 2003 to $2008(s=6.097, p=0.05)$ and a median $>95 \%$ was still registered in 2008, showing that the phenomenon remains widespread in the study area (Fig. 2).

When sampling sites are analysed separately, several differences in both genders SH are registered (Table 1). Mean ${ }^{t} \mathrm{SH}$ variation at St. 7 can explain the difference also registered in MPL at that site (Table 2): males collected in 2006 were larger than the ones in 2003 and MPL is also significantly higher in 2006. However, other MPL significant variations between years are not simply justified by differences in ${ }^{\top} \mathrm{SH}$. Regarding mean ISH (Table 1), with the exception of St. 13 and 16 (between 2003 and 2006) and of St. 10 (between 2006 and 2008) where animals collected in the last campaign were smaller (in 2006 and 2008, respectively), all significant differences were towards increasing animal size. In turn, with the exception of St. 15 where significant increases were registered in both FPL and VDSI between 2003 and 2006, all significant differences in imposex indices were towards a reduction (Table 2). Briefly, VDSI $>2$ was registered at $68.75 \%$ of the sampled sites in 2003 , at $56.25 \%$ in 2006 and at $16.67 \%$ in 2008 (see Table 2). The relative frequencies of the VDS stages are plotted in Fig. 3 for an overview of their individual evolution over time.

The ordered logit regression model was implemented to remove the effect of animal size on the evaluation of imposex temporal trends. Absolute frequencies of VDS stages exhibited by all females (of all sizes) analysed from each sampling site are presented in Table 3, together with the model estimation results. The algorithm was not able to converge in St. 1, 5, 10, 12 and 13 (Table 3). Shell height ( $\mathrm{SH}$ ) proved to be always positively and highly significantly associated with the VDS level, meaning that this variable should always be incorporated on VDS stage modelling (see SH coefficients and respective $p$-values estimated for all the sampling sites in Table 3). At St. 2, 6, 9 and 11 there is a significant decrease of VDS between 2003/2006, 2003/2008 and 2006/2008 (Table 3). Similarly, there is a significant decrease of VDS at St. 3-4 and 7 from 2003 to 2006 (the only years that were sampled as these sites were not revisited in 2008; Table 3). At St. 8 there is also a significant decrease of the VDS level between 2003/2006 and 2003/2008 although there is no statistical difference between 2006/2008 ( $p$-value $=0.415$; Table 3). Animals at St. 14 were only collected in 2003 and 2006 and there is no significant difference of VDS levels between these years at this site. At St. 15 there was a highly significant increase in VDS between 2003/2006 and 2003/2008, but no significant difference between 2006/2008 ( $p$-value $=0.860$; Table 3$)$. Probabilities of females presenting VDS $>2$ were also estimated by the model, for animals of a given $\mathrm{SH}$, at each sampling site and year (Table 3). The SH value for which the probability was estimated corresponds to the mean $\mathrm{SH}$ of adult animals (from the $\mathrm{SH}$ at sexual maturation to the maximum collected) at each site (Table 3). We choose females VDS $>2$ as they shift the VDSI to values higher than 2 , which is the limit between OSPAR classes B and $\mathrm{C}$ (details will be published elsewhere). The probability of occurring adult females with VDS $>2$ varied between $27-100 \%$ in $2003,5-95 \%$ in 2006 and $4-94 \%$ in 2008 (Table 3). This probability decreased consistently from 2003 to 2008, with the exception of St. 2 and 15. Finally, making the model algorithm much more powerful, all the observations coming from all the sites common to 2003, 2006 and 2008 were pooled (St. 1-2, 5-6, 8-13 and 15-16; Table 3). A highly significant decrease of the VDS level is estimated for the years being compared ('2003/2006', '2003/2008' and '2006/2008'; see Table 3). Globally, the probability of females presenting VDS > 2 for a mean SH of $22.64 \mathrm{~mm}$ in the study area decreased from $68.8 \%$ in 2003 to $28.9 \%$ in 2006 and to $16.6 \%$ in 2008 (Table 3).

\section{Discussion}

\section{Imposex evolution from 2003 to 2008}

$N$. lapillus imposex levels in 2006 and 2008 were higher at sites near harbours, a tendency earlier reported in $2000^{28}$ and $2003,{ }^{23}$ corroborating previous studies that identify larger vessels' AF systems as the main TBT environmental source along the Portuguese coast. ${ }^{14-16,21,23,28-35}$ Although imposex levels in the study area did not change significantly between 2000 and $2003,{ }^{23}$ a general decline of imposex intensity along the Portuguese coast is found in the present study from 2003 to 2008 (Fig. 2), suggesting that the EU Regulation No. 782/2003 was effective in reducing TBT pollution. This measure prohibited OT AF

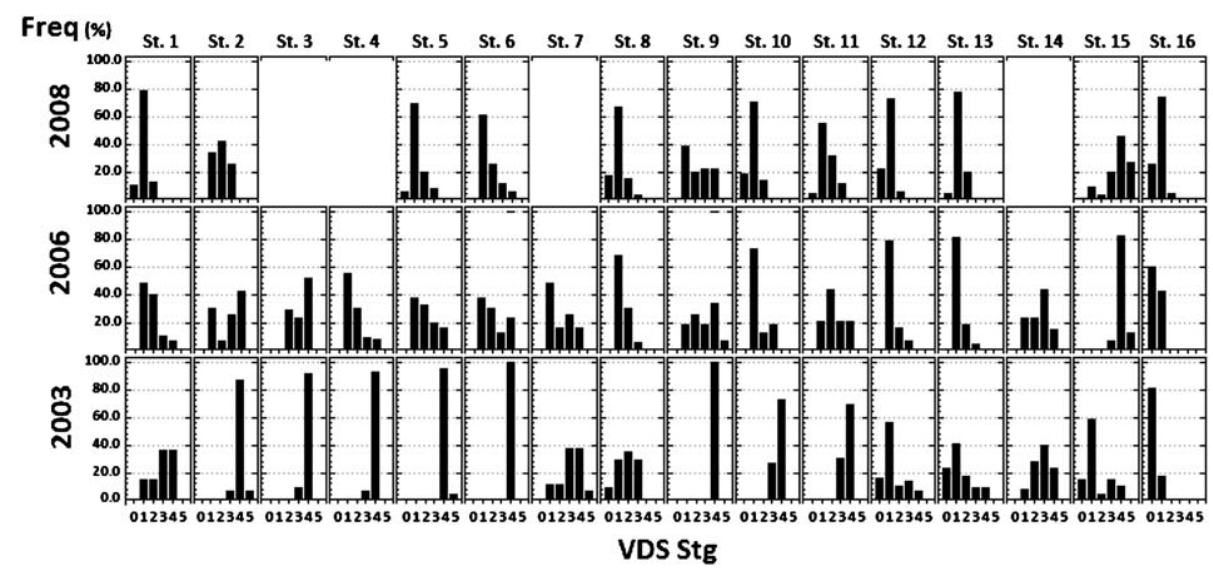

Fig. 3 Relative frequency (Freq.) of each VDS stage exhibited by females collected in $2003,{ }^{23} 2006$ and 2008 at St. 1-16. For total number of specimens (n) at each site and year see Table 1, and for additional information on sites location see Fig. 1A. 


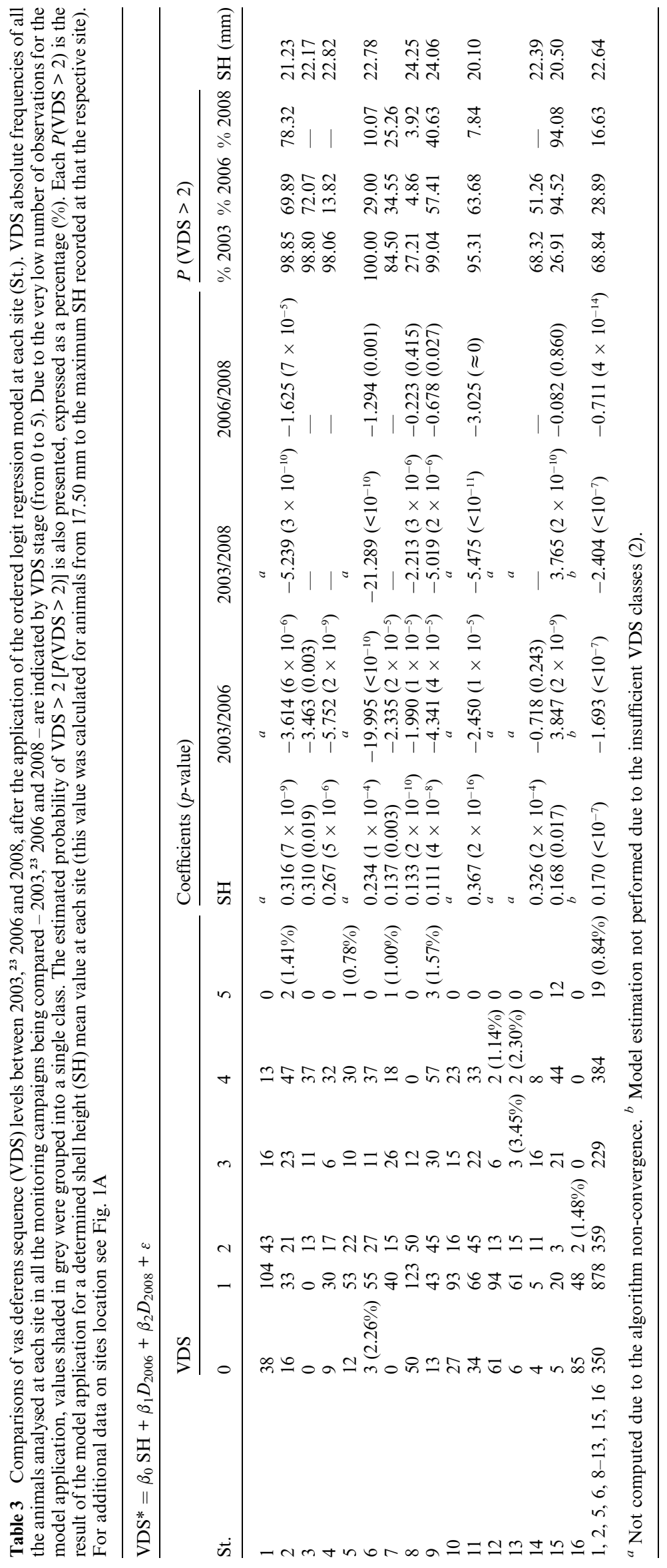


painting but did not ban completely the use of OT AF systems, since vessels could still bear TBT in their hulls until 17 September 2008 (the date when the IMO ban entry came into force). This may partly explain why OTs were still ubiquitous in seawater throughout the Portuguese coast in 2006 and concentrations continued to be higher at sites located inside port terminals or in their vicinity (Fig. 1D). OT mean concentrations in sub-surface waters in 2006 varied from 0.7 to $140.8 \mathrm{ng} \mathrm{Sn}$ per 1, the major fraction of which is known to be butyltins, as other OT species are almost negligible in quantity along the Portuguese coast. ${ }^{15,34,35}$ However, vessels may not be the only source for these recent TBT inputs. Some authors still consider that after the IMO ban entry came into force TBT inputs were maintained by other sources, namely: (i) release from dockyard facilities as a result of the removal of old coatings in dry dock; ${ }^{36}$ (ii) the remobilization from sediments to the water column, ${ }^{37,38}$ (iii) some illegal use; and (iv) other sources such as preservative or disinfecting agents..$^{15}$ Imposex reductions from 2003 to 2008 are noticeable mainly in the north and central coasts of Portugal (see Fig. 1C and 3 and Table 2), regions where the most important harbours are located and so where a higher number of sites were sampled, compared with the south. Thus, the statistically suggested overall decline in imposex levels is probably influenced by this higher number of samples in the north/centre of Portugal. In fact, a dramatic raise in VDSI and \%S was registered at St. 15 from 2003 to 2006, values that remained high in 2008; besides, a higher frequency of successively advanced VDS stages was also recorded at St. 16 over time (Fig. 3), although this was not significant in terms of VDSI increase (Table 2). In the south, an almost threefold increase in ships and respective gross tonnage was registered at Sines harbour (north of St. 15) between 2003 and 2008, and a twofold increase at Portimão harbour (southeast of St. 16) from 2003 to 2006 (see Fig. 4). This fact, associated with an increase in ship traffic in routes accessing these ports, could ultimately be the cause of the increase of imposex levels at St. 15 and 16. Nevertheless, St. 15 remains under study, since such increases in both imposex intensity and female sterility are

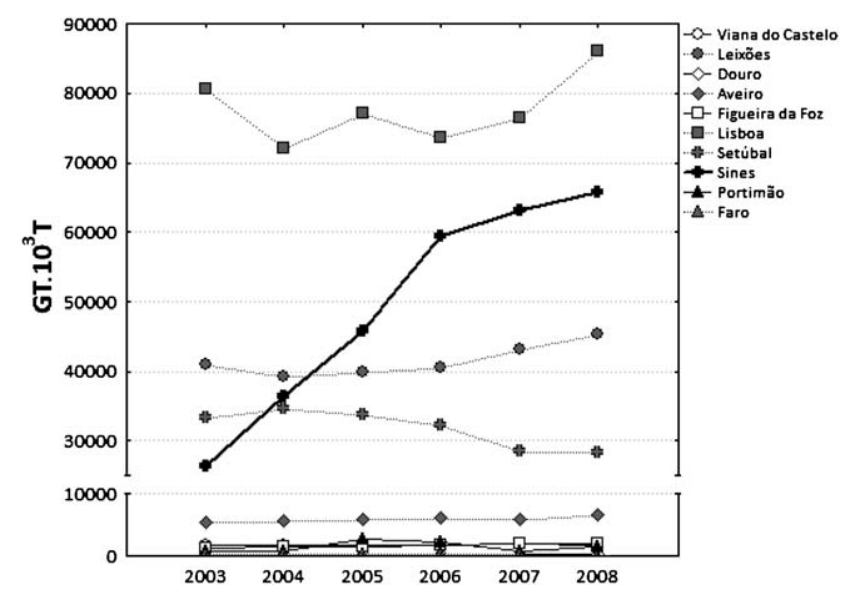

Fig. 4 Gross tonnage expressed in tons (GT.103 T) of commercial ships entering and leaving the Portuguese main harbours: temporal evolution from 2003 to 2008 indicated by port. Data published by Instituto Nacional de Estatística (INE) and obtained from the institution website (www.ine.pt). considered extreme even considering increased naval traffic in the region. St. 14 is closer to Sines harbour but, on the other hand, it is inside the Mira estuary, which does not have any large maritime infrastructure, and is therefore perhaps protected from the influence of Sines port, considering the high level of mixing of fresh water and seawater, justifying imposex intensity maintenance from 2003 to 2006.

\section{Effect of specimen size in the VDSI assessment}

The reliability of using $N$. lapillus for monitoring TBT pollution requires control of factors known to cause some bias in imposex assessment. For instance, penis-based indices like RPSI (directly dependent on FPL and MPL measurements) are difficult to manage since PL is affected by animal size, sexual maturation and reproductive cycle seasonality in both genders and by the distance to egg-capsule clusters in males. ${ }^{14,20}$ The current study shows that the VDS stage (and consequently the VDSI) is also dependent on animal size ( $\mathrm{SH}$ ), (see the 'SH' coefficient and respective $p$-value column in Table 3). This can be problematic, since imposex assessment at a given site is generally carried out using adult animals that rarely have uniform sizes. One procedure to overcome this problem, when performing temporal trend analysis, is to avoid making imposex comparisons when significant differences in $\mathrm{SH}$ are detected between two or more sampling dates. In many cases the SH differences are not significant due to the low number of animals in the samples (which in its turn is also inappropriate). A common procedure is to conduct the temporal analysis but be aware of possible bias caused by differences in shell size (see Table 1 and Fig. 2). Seeking for a better approach, in the current work we used an innovative statistical method to analyse VDS data: we consider the $\mathrm{SH}$ as a regressor in latent VDS modelling in order to control its effect on temporal comparisons. Looking at St. 8 as an example, through the commonly used data analysis, and

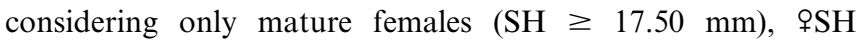
increased significantly from 2003 to 2006 and no difference was observed in VDSI between those years using a non-parametric Kruskal Wallis test. Knowing that $\mathrm{SH}$ is positively correlated with the VDS stage, if \%SH had not been higher in 2006, a significant decrease in VDSI from 2003 to 2006 could have been registered, as it was when VDS stage was estimated by the latent VDS (VDS*) model (see the St. 8 '2003-2006' coefficient and respective $p$-value in Table 3).

\section{Evolution of the Portuguese coast ecological quality (EcoQ)}

As initially referred, the OSPAR Commission developed Environmental Assessment Criteria for imposex, taking into account the objectives of the OSPAR Hazardous Substances Strategy and the existing Ecotoxicological Assessment Criteria ${ }^{39}$ for TBT in water (upper EAC $=0.04 \mathrm{ng}$ Sn per 1), sediment and biota. For $N$. lapillus, assessment criteria classes are: Class A corresponding to VDSI C [0, 0.3[; Class B to VDSI C [0.3, 2.0[; Class C to VDSI C [2.0, 4.0[; Class D to VDSI C [4.0, 5.0]; Class E to VDSI > 5.0. In retrospect, in $2003^{23} \mathrm{~N}$. lapillus exhibited VDSI between VDSI $\geq 2.0$ at about $70 \%$ of the surveyed sites falling into Classes $\mathrm{C}$ and $\mathrm{D}$ and indicating exposure to TBT concentrations higher than the EAC. The present study shows an evident decline 
in TBT pollution in the following years: VDSI $\geq 2.0$ was just reported at $56 \%$ of the sampled sites in 2006, and in 2008 this percentage decreased to $17 \%$.

VDS latent modelling also allows environmental risk evaluation by estimating the probability of a VDS stage above the EcoQO for imposex in $N$. lapillus; thus we consider that specimens with VDS stage $>2$ may indicate somehow an insufficient Ecological Quality (EcoQ) of the study area. Regarding the ordered logit regression model estimations, for the whole study area, the probability of VDSI $>2$ in a putative adult of $\mathrm{SH}=$ $22.64 \mathrm{~mm}$ decreased from $68.8 \%$ in 2003 to $16.6 \%$ in 2008 , corroborating the previous conclusion that a general amelioration of the EcoQ occurred in the sampling sites surveyed in the Portuguese coast.

\section{Conclusions}

The current study shows that Nucella lapillus populations sampled along the Portuguese mainland coast are still extensively affected by imposex and that, even three years after the European ban on TBT, fresh inputs continued to occur. Nevertheless, changes in imposex levels indicate a decline in TBT pollution in the north and central coasts from 2003 to 2008.

\section{Acknowledgements}

The authors are deeply grateful to the assistance of Ana Sousa, Ascensão Ravara and Ionut Marcovici during sampling campaigns. This work was supported through a $\mathrm{PhD}$ grant to Susana Galante-Oliveira (SFRH/BD/18411/2004) attributed by the Portuguese Foundation for Science and Technology (FCT) founded by the Portuguese Government and the research project POCI/MAR/61893/2004 financed by the FCT and by the POCI 2010, co-financed by FEDER.

\section{References}

1 D. M. Yebra, S. Kiil and K. Dam-Johansen, Prog. Org. Coat., 2004, 50, 75-104.

2 B. S. Smith, Proc. Malacological Soc. London, 1971, 39, 377-378.

3 B. S. Smith, J. Appl. Toxicol., 1981, 1, 141-144.

4 G. W. Bryan, P. E. Gibbs, L. G. Hummerstone and G. R. Burt, $J$. Mar. Biol. Assoc. U. K., 1986, 66, 611-640.

5 P. E. Gibbs and G. W. Bryan, J. Mar. Biol. Assoc. U. K., 1986, 66, 767-777.

6 IMO, International Maritime Organization, Ref. No. AFS/CONF/ 26, London, 2001, pp. 1-28.

7 IMO, Summary of Conventions as at 2nd November 2009, available from: http://www.imo.org/conventions/mainframe.asp?topic_id = 247 (accessed 10.10.09), International Maritime Organization, London, 2009.

8 OSPAR, List of Chemicals for Priority Action, Agreement Ref. No. 2004-12 Update 2007), OSPAR Commission, London, 2007.
9 Official Journal of the European Communities, Ref. No. OJ L 327 , 2000, pp. 1-73.

10 OSPAR, Coordinated Environmental Monitoring Programme (CEMP), Ref. No. 2008-08), OSPAR Commission, London, 2008.

11 P. E. Gibbs, G. W. Bryan, P. L. Pascoe and G. R. Burt, J. Mar. Biol. Assoc. U. K., 1987, 67, 507-523.

12 OSPAR, JAMP Guidelines for Contaminant-Specific Biological Effects, Agreement Ref. No. 2008-09, OSPAR Commission, London, 2008.

13 OSPAR, Background Document on the Ecological Quality Objective on imposex in dog whelks Nucella lapillus, Publication No. 2005/247, OSPAR Commission, London, 2005.

14 S. Galante-Oliveira, I. Oliveira, N. Jonkers, M. Pacheco and C. M. Barroso, J. Environ. Monit., 2009, 11, 1405-1411.

15 A. Sousa, F. Laranjeiro, S. Takahashi, S. Tanabe and C. M. Barroso, Chemosphere, 2009, 77, 566-573.

16 M. Rato, N. Ferreira, J. Santos and C. Barroso, J. Environ. Monit., 2009, 11, 100-107.

17 A. Minchin and I. M. Davies, J. Environ. Monit., 1999, 1, 239-241.

18 A. Minchin and I. M. Davies, J. Environ. Monit., 1999, 1, 203-205.

19 S. Galante-Oliveira, PhD Thesis, University of Aveiro, Aveiro, Portugal, 2010.

20 S. Galante-Oliveira, I. Oliveira, J. A. Santos, M. L. Pereira, M. Pacheco and C. Barroso, J. Environ. Monit., 2010, 12, 1055-1063.

21 S. Galante-Oliveira, I. Oliveira, M. Pacheco and C. Barroso, J. Environ. Monit., 2010, 12, 500-507.

22 P. E. Gibbs, in ICES Techniques in Marine Environmental Sciences Biological effects of contaminants: Use of imposex in the dogwhelk (Nucella lapillus) as a bioindicator of tributyltin pollution, International Council for the Exploration of the Sea, Copenhagen, Denmark, 1999, vol. 24, pp. 1-29.

23 S. Galante-Oliveira, W. J. Langston, G. R. Burt, M. E. Pereira and C. M. Barroso, Appl. Organomet. Chem., 2006, 20, 1-4.

24 C. M. Barroso and M. H. Moreira, J. Mar. Biol. Assoc. U. K., 1998, 78, $1233-1246$.

25 G. S. Maddala, Limited-Dependent and Qualitative Variables in Econometrics, Cambridge University Press, Cambridge, 1983.

26 A. Agresti, Categorical Data Analysis, 2nd edn, John Wiley \& Sons, New Jersey, 2002

27 J. Long, Regression Models for Categorical and Limited Dependent Variables, SAGE Publications Inc., Bloomington, 1997.

28 C. M. Barroso and M. H. Moreira, Mar. Pollut. Bull., 2002, 44, 480486.

29 C. M. Barroso, M. H. Moreira and P. E. Gibbs, Mar. Ecol.: Prog. Ser., 2000, 201, 221-232.

30 C. M. Barroso, M. H. Moreira and M. J. Bebianno, Mar. Ecol.: Prog. Ser., 2002, 230, 127-135.

31 A. Sousa, S. Mendo and C. Barroso, Appl. Organomet. Chem., 2005, 19, 315-323.

32 M. Rato, M. B. Gaspar, S. Takahashi, S. Yano, S. Tanabe and C. Barroso, Mar. Pollut. Bull., 2008, 56, 1323-1331.

33 M. Rato, A. Sousa, R. Quinta, W. J. Langston and C. M. Barroso, Environ. Toxicol. Chem., 2006, 25, 3213-3220.

34 A. Sousa, T. Ikemoto, S. Takahashi, C. Barroso and S. Tanabe, Mar. Pollut. Bull., 2009, 58, 1130-1136.

35 A. Sousa, C. Matsudaira, S. Takahashi, S. Tanabe and C. Barroso, Mar. Pollut. Bull., 2007, 54, 1645-1653.

36 A. Kotrikla, J. Environ. Manage., 2009, 90, S77-S85.

37 W. J. Langston and N. D. Pope, Mar. Pollut. Bull., 1995, 31, 32-43.

38 J. M. Ruiz, R. Barreiro, L. Couceiro and M. Quintela, Chemosphere, 2008, 73, 1253-1257.

39 R. B. J. Peachey, Mar. Pollut. Bull., 2003, 46, 1365-1371. 